\title{
MOGUĆNOSTI PRIMJENE LAKIH BESPILOTNIH LETJELICA U PREBROJAVANJU KRUPNE DIVLJAČI
}

\author{
POSSIBILITIES OF APPLYING LIGHTWEIGHT UNMANNED \\ AERIAL VEHICLES TO BIG GAME COUNTING
}

Kristijan TOMLJANOVIĆ*, Helena NOSEK, Renata PERNAR, Marijan GRUBEŠIĆ

\begin{abstract}
SAŽETAK
U provedenom istraživanju pokušalo se istražiti u kojoj mjeri je moguće aplicirati sustav bespilotne letjelice opremljene termalnom kamerom u procjeni nekih populacijskih parametara krupne divljači. Istraživanje je provedeno u nizinskom području kontinentalnog dijela Republike Hrvatske unutar lovišta Opeke II. Za istraživanje je odabrana divlja svinja kao najčešća vrsta krupne divljači u Republici Hrvatskoj. Unutar dva lokaliteta (I dobni razred,uređajni razred hrasta lužnjaka) provedeno je testiranje dvije metode prebrojavanja. Prvom metodom pokušala su se prebrojiti sva grla unutar istraživanog odsjeka. Rezultati dobiveni tom metodom pokazuju relativno visoku brojnost divlje svinje od prosječno 1,26+/-0,18 grla/ha unutar istraživanjem obuhvaćenog područja. Druga korištena metoda predstavlja prebrojavanje divljih svinja na unaprijed određenim prugama, čiji udio u ukupnoj promatranoj površini iznosi $10 \%$. Kod te metode podaci su veće varijabilnosti te je ustanovljena nešto manja brojnost divljih svinja unutar promatranog odsjeka od $0,61 \mathrm{grla} / \mathrm{ha}$ uz vrlo visok $s d=+/-0,53$. Istraživanjem je potvrđena mogućnost primjena sustava bespilotnih letjelica s termalnim kamerama. Od dvije primijenjene metode, prva (apsolutno prebrojavanje svih životinja) je pogodna za manje površine, dok je metoda primjernih pruga pogodna za veće površine uz svjesni rizik generiranja veće pogreške prebrojavanja.
\end{abstract}

KLJUČNE RIJEČI: bespilotna letjelica, lovno gospodarenje, daljinska istraživanja, divlja svinja (Sus scrofa), prebrojavanje divljači

\section{UVOD}

\section{INTRODUCTION}

U istraživanju divljih životinja koriste se različite tehnike i tehnologije. Ciljevi takvih istraživanja ili monitoringa su različiti, a najčešći su predmet interesa brojnost po površini i veličina populacije istraživane vrste (Myslenkov i Miquelle, 2015). Razvojem novih tehnika i tehnologija, koje se svakodnevno koriste u praktičnom monitoringu divljih životinja, mnogi poslovi postaju lakši i precizniji, uporaba tehnologije često smanjuje potrebu za brojem ljudi koji su- djeluju u istraživanju, a neke do sada neizvodive metode su realna stvarnost. U posljednje vrijeme jedna od novih tehnologija daljinskih istraživanja, čija primjena i širok spektar mogućnosti se još uvijek istražuje je i uporaba lakih bespilotnih letjelica, u literaturi najčešće spominjanih kao $L i$ ghtweight unmanned aerial vehicles (UAV s ili drones). Istraživanje divljih životinja korištenjem lakih bespilotnih letjelica je neinvazivan i relativno siguran način, koji osigurava dobru preglednost prostora iz zraka i danas ima već ustaljenu primjenu u agronomiji i šumarstvu. Bilo koji oblik

\footnotetext{
* Dr. sc. Kristijan Tomljanović, mag. ing. silv. Helea Nosek, prof.dr. sc. Renata Pernar, prof. dr. sc. Marijan Grubešić, Šumarski fakultet Zagreb, Svetošimunska 25, 10000 Zagreb, corresp. autor email: tomljanovic@sumfak.hr
} 
vegetacijskog pokrova je moguće snimati iz zraka omogućujući na taj način jeftin i precizan oblik monitoringa i pridobivanja različitih informacija o istom (Gašparović i sur., 2017). Značajna prednost je i mogućnost uvida teško dostupnih i udaljenih površina, kao i približavanje osjetljivim ili agresivnim vrstama (Chabot i Bird, 2015.). Razvojem termalnih kamera namijenjenih korištenju s lakih bespilotnih letjelica, otvorila se mogućnost detekcije divljih životinja, koje žive unutar šumskih ekosustava i koji se teško mogu detektirati iz zraka korištenjem klasičnih kamera koje su osjetljive na spektralne kanale u vidljivom dijelu spektra(npr. RGB kamere). Tehnologija snimanja divljih životinja iz zraka daje mogućnost utvrđivanja veličine populacije i njezine interakcije sa staništem na otvorenim površnama poput ptica (Grom et al., 2013), a sada korištenjem termalnih kamera i tipično šumskih životinja poput krupnih dvopapkara ili krupnih predatora. Najčešće korištena uobičajena metoda utvrđivanja brojnosti krupnih vrsta divljači je metoda osmatranja s osmatračnica u redovitim vremenskim intervalima, metoda identificiranja i brojanja izmeta, metoda prebrojavanja na transektima, Lincon - Petersonova metoda (cach - release - cach) (Sutherland, 2006), korištenje senzornih kamera (Jacobson i sur., 1997; Karanth i sur., 2006; Tomljanović i sur., 2010; Plhal i sur. 2011) i druge. U novije vrijeme se koriste i metode DNK analize kako bi se utvrdila brojnost nekih vrsta sa širokim radijusom kretanja i male gustoće populacije kao što su krupni predatori (Miller i sur., 2005; Caniglia, 2008). Utvrđivanje brojnog stanja parnoprstaša ili krupnih predatora često se provodi iz različitih razloga, a često takva prebrojavanja korištenjem konvencionalnih metoda u šumskim ekosustavima ovise o financijskim sredstvima, raspoloživosti ljudi, gustoći populacije vrste koja se prebrojava itd.

S obzirom da daljinska istraživanja krupne divljači korištenjem termalnih kamera na bespilotnim letjelicama gotovo da i ne postoje, ovdje se pokušala utvrditi operativna primjenjivost takvog sustava. Za objekt istraživanja odabrana je divlja svinja (Sus scrofa) kao jedna od najčešćih vrsta krupne divljači u Europi,koja se u mnogim državama tretira kao štetnik, osobito u poljoprivredi, što je jedan od razloga nužnosti poznavanja brojnog stanja te vrste (Seward i sur., 2004.) Divlja svinja vrsta je široke ekološke valencije, koja u prirodi naraste i preko 200kg. Kako je svejed, dio dnevnih potreba zadovoljava uzimajući biljnu hranu (sjeme, zeleni biljni dijelovi, korijen), dok dio potreba zadovoljava i uzimanjem hrane animalnog porijekla (ličinke, crvi, gliste, kukci, sitni glodavci) (Massei i Genov, 2004). Iz tog razloga divlja svinja često se nastanjuje u vlažnim šumskim staništima, gdje u površinskim slojevima tla ima mogućnost rovanja za hranom, što istovremeno zbog uvjeta staništa otežava utvrđivanje populacijskih parametara.

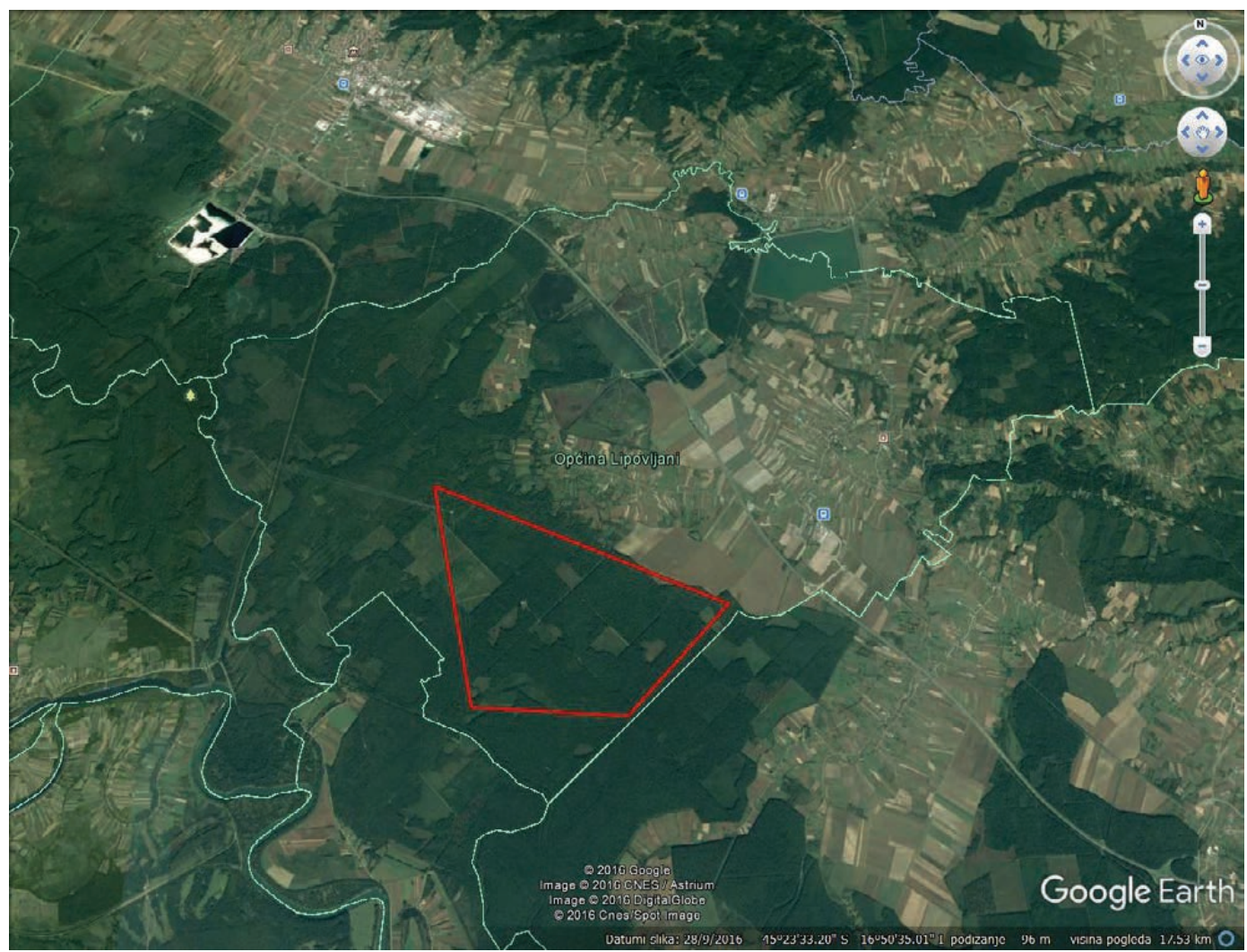

Slika 1: Područje istraživanja (crvenom linijom zaokruženo je šire područje istraživanja). Izvor: Google Earth, http://earth.google.com Figure 1: Area of investigation (the red line denotes a wider area of research). Source: Google Earth, http://earth.google.com 


\section{MATERIJALI I METODE MATERIAL AND METHODS}

\section{Područje istraživanja - Research area}

Za područje istraživanja je odabrano nizinsko lovište u predjelu Sisačko - moslavačke županije broj: III/39 „Opeke II“. Lovištem gospodari Šumarski fakultet u Zagrebu, te je prema važećoj lovnogospodarskoj osnovi (Tomljanović, 2016) matični fond divlje svinje u lovištu procijenjen na 200 grla. Prosječna nadmorska visina šireg prostora je od 95 100 n.m.v. Uz hrast lužnjak (Quercus roboris L.) dominantnu vrstu drveća čini poljski jasen (Fraxinus angustifolia L.). Glavne biljne zajednice lovišta čine nizinska šuma hrasta lužnjaka i velike žutilovke (Genisto elate - Quercetum roboris), šuma hrasta lužnjaka i običnoga graba (Carpino betuliQuercetum roboris /Anić 1959/ Rauš 1969) te u vlažnijim i nešto nižim dijelovima šuma poljskoga jasena s kasnim drijemovcem (Leucoio-Fraxinetum angustifoliae Glav. 1959). Prama važećoj lovnogospodarskoj osnovi prilike u staništu su opisane kao vrlo dobre za uzgoj divlje svinje.

\section{Bespilotna letjelica - drone}

Lake bespilotne letjelice ili bespilotni zrakoplovi I. klase (do 5 kg ukupne mase), kako ih klasificira Pravilnik o sustavima bespilotnih zrakoplova (Anonimus 2015) u literaturi se često nazivaju različitim imenima poput UAV (Unmanned Aerial Vehicles ili bespilotne letjelice), UAS (Unmanned Aircraft Systems ili sustavi bespilotnih letjelica), i nešto rijeđe RPV (Remotely Piloted Vehicles ili daljinski pilotirana vozila)(Paneque-Gálvez i sur., 2014). Uobičajeni naziv „dron“ potječe od američke vojske, koja ga je prva aplicirala kao UCAV (Unmanned combat aerial vehicle ili bespilotna borbena letjelica), combat drone (bespilotno borbeno sredstvo napada) ili samo drone (dron) (Dowd 2014). Prema Miller i sur. (2005), bespilotna letjelica (engl. Unmanned Aerial Vehicle - UAV) je zračna letjelica teža od zraka, pogonjena vlastitim pogonom ili zrakoplov bez posade, koji se može nadzirati na daljinu ili letjeti samostalno uporabom unaprijed programiranog plana leta ili pomoću složenih autonomnih dinamičkih sustava. Dok je za korištenje zračnog prostora (letenje) nadležna Agencija za civilno zrakoplovstvo, snimanje iz zraka je regulirano uredbom Državne geodetske uprave (Anonimus 2016).

Za ovo istraživanje korišten je quadcopter DJI Inspire opremljen Zenmuse xt termalnom kamerom. Kamera ima mogućnost snimanja u rezoluciji 640x512 uz full frame od $30 \mathrm{~Hz}$. Osjetljivost $(\mathrm{NEdT})<50 \mathrm{mK}$ pri f/1.0. Kut snimanja kamere je relativno uzak i pri visini leta od $100 \mathrm{~m}$ pokriva se linija duljine $22,4 \mathrm{~m}$. Za let su korištene dvije različite baterije TB47 (4500 mAh) i TB48 (5700 mAh). Baterije iako potpuno iste mase i konstrukcije su značajno različitog kapaciteta te se jača pokazala kao bolji izbor, osiguravajući dulju autonomiju leta. Upravljačka konzola (daljinski) osim za upravljanje služi i za prijem video signala kamere s letjelice. Operativna frekvencija rada iznosi $5,728-5,850 \mathrm{GHz}$ i $2,400-2,483 \mathrm{~Hz}$.

\section{METODE METHODS}

Metoda prebrojavanja morala je biti prilagođena ograničavajućim faktorima letjelice, ponajprije kapacitetu baterije koja osigurava sigurnu autonomiju leta od oko $20 \mathrm{~min}$. Ograničavajući faktor u nekim slučajevima može biti i doseg telemetrije odnosno upravljanja, koja teorijski iznosi preko 2,5 km međutim, u realnim uvjetima nizinskog šumskog staništa tijekom ovog istraživanja to se pokazalo kao $600-700 \mathrm{~m}$. Područje koje se pritom može pokriti, izravno ovisi o brzini i visini leta, a neizravno o temperaturi koja je od velikog utjecaja na kapacitet baterija, što je uočeno, ali nije posebno istraživano. Za prebrojavanje korištene su dvije metode. Prva metoda sastojala se od nesistematskog letenja nad odabranim područjem (branjevina), gdje se očekuje povećana koncentracija istraživane divljači. Bespilotna letjelica podigla bi se na određenu visinu, pokrivajući slikom pritom određeno područje poznate površine ${ }^{1}$. Podizanjem letjelice na više visine leta dobiva se pregled nad većim prostorom, ali se smanjuje mogućnost detekcije snimane divljači i obrnuto. Nakon što bi se letjelica podigla na određenu visinu, vršilo se okretanje letjelice oko osi y i kamere oko osi x te na taj način vršila detekcija i prebrojavanje divljači unutar snimane površine. Stavljanjem u odnos broja snimljene (prebrojane) divljači na snimci, s površinom obuhvaćenom snimanjem dobivena je relativna brojnost divljači na snimanoj površini $N=\frac{n}{P}$ pri čemu je $\mathrm{N}=$ relativni broj divljači po površini, $\mathrm{n}=$ prebrojane jedinke na snimanoj površini, $\mathrm{P}=$ površina obuhvaćena snimanjem.

Druga metoda koja se može koristiti na većim površinama predstavlja modificiranu metodu primjernih ploha. Metoda predstavlja sistematski let i snimanje po unaprijed određenim pravcima (transektima).S obzirom da je u ovom istraživanju letjelica opremljena GPS-om, unaprijed je programiran let po transektima pri određenoj brzini i visini nad odabranim područjem. Pri tome je potrebno odrediti intenzitet kojim se snima odabrano područje. Ovdje je važna visina leta, jer za kameru koja je korištena na visini od 100m krajnji rubovi snimke pokrivaju širinu teorijske pruge od $22,4 \mathrm{~m}$, što je važan faktor kod planiranja intenziteta. Naknadno, nakon što je snimanje u sklopu ovog istraživanja već obavljeno, pojavio se i program kojim je moguće izravno 
odredit intenzitet snimanja, što znatno olakšava primjenu metode. Za izračun relativne brojnosti divljači korištena je ista formula kao i kod prethodne metode, samo je u ovom slučaju površina snimanja bila računata iz ukupne duljine snimanja i širine snimane pruge $\left(\mathrm{P}_{\text {uzorka }}=\right.$ širina pruge na kojoj se snima $\mathrm{x}$ ukupna duljina pruge snimanja). Iz toga proizlazi da je $N=\frac{n}{P}$, gdje je $\mathrm{N}=$ broj divljači na površini za koju se vrši prebrojavanje, $\mathrm{n}=$ broj opaženih jedinki na plohama (transektima), $\mathrm{P}=$ ukupna površina transekata odnosno površina uzorka. Za takav oblik prebrojavanja moguće je izračunati i standardnu devijaciju:

$s_{d}=\sqrt{\frac{\sum(x-\bar{x})^{2}}{n-1}} \quad \begin{aligned} & \text { pri čemu je: } s_{\mathrm{d}}=\text { standardno odstupanje } \\ & \text { od aritmetičke sredine }\end{aligned}$ $\mathrm{x}=$ broj jedinki prebrojanih na plohi dok je $\mathrm{n}=$ broja uzoraka

U oba slučaja provođena su uzastopna snimanja s različitih visina, kako bi se isprobala mogućnost uočavanja i detekcije divlje svinje.

\section{REZULTATI RESULTS}

Na odabranom području u razdoblju od studenog 2017. god. do siječnja 2018. god. izvršeno je ukupno 20 naleta u svrhu prebrojavanja. Deset naleta bilo je u svrhu prebrojavanja divljači metodom apsolutnog brojanja na plohi poznate površine, dok je 10 letova bilo prebrojavanje na transektima. Za testiranje metode apsolutnog prebrojavanja na plohi poznate površine, određen je odsjek prvog dobnog razreda površine 15,4 ha. Na toj plohi izvršeno je 10 sukcesivnih prebrojavanja. Rezultati su prikazani u grafikonu 1.

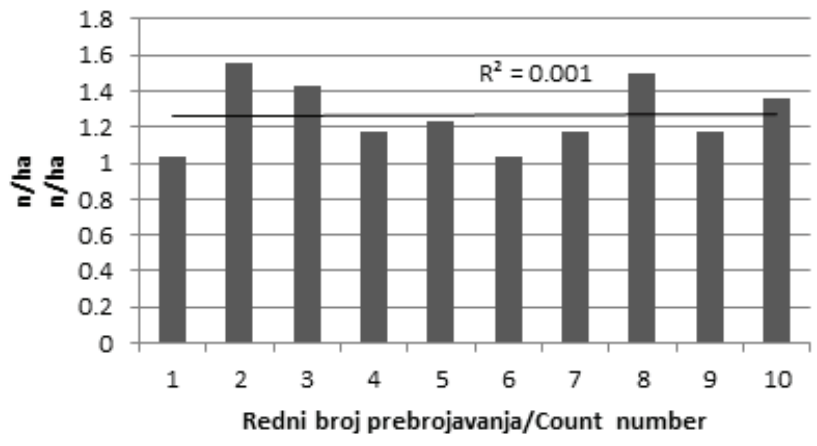

Graf 1: Prikaz brojnosti divlje svinje po hektaru istraživane površine kod metode apsolutnog prebrojavanja na površini.

Graph 1: Number of wild boars per hectare of the research areadetected using the absolute counting method.

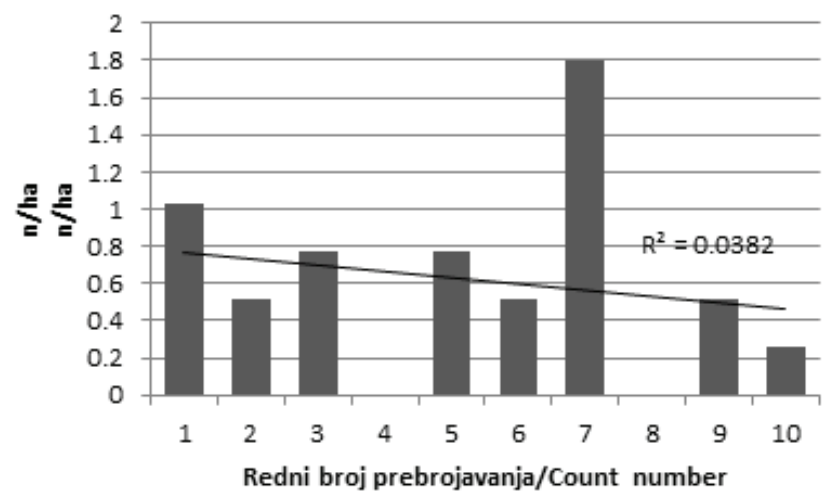

Grafikon 2: Prikaz brojnosti divlje svinje po hektaru istraživane površine kod metode prebrojavanja na transektima.

Graph 2: Number of wild boars per hectare of the research area detected using the transect counting method.

Tijekom provedenih prebrojavanja brojnost divlje svinje na promatranoj površini kretala se u rasponu od $16-24$ grla

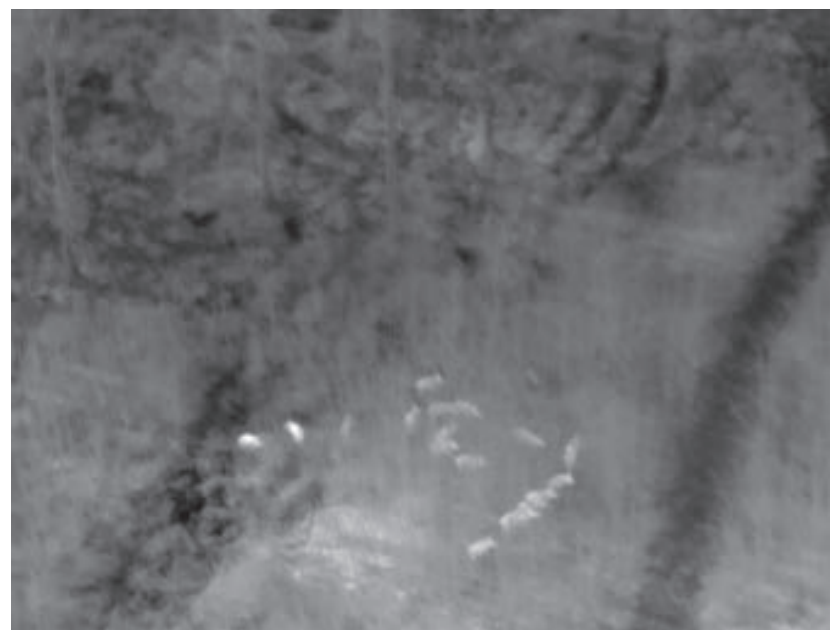

${ }^{2}$ Slika 2 i 3: Divlje svinje snimljene metodom apsolutnog brojanja na plohi poznate površine

Figures 2 and 3: Wild boars recorded by the absolute counting method on the plot of the known area

${ }^{2}$ Fotografije korištene u istraživanju odobrene su za uporabu od strane Državne geodetske uprave. 

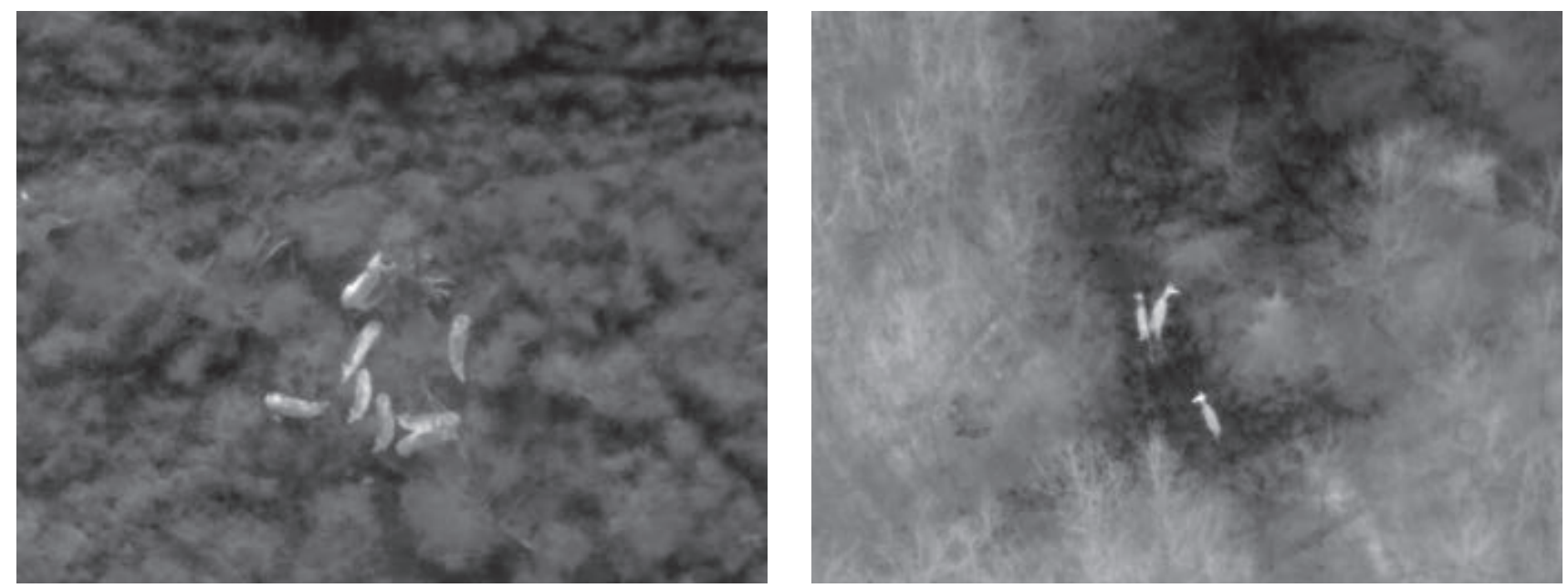

Slika 4 i 5: Metoda transekta, krdo divljih svinja (slika lijevo), tri jedinke jelena običnog (slika desno) Figures 4 and 5: Transect method, herd of Wild boars (left image), and three Red deer (right image)

uz aritmetičku sredinu od 19,5 grla. Relativna brojnost iznosila je $1,26+/-0,18$ grla po hektaru.

Testiranje metode prebrojavanja na transektima provedeno je na površini od 39,5 ha. Radilo se o dva povezana odsjeka prvog dobnog razreda. Na istraživanoj površini provedeno je ukupno 10 sukcesivnih prebrojavanja na transektima uz intenzitet pokrivanja površine od $10 \%$. Brojnost dobivena na primjernim plohama razmjerno intenzitetu preračunavana je za cijelu istraživanu površinu. Rezultati su prikazani u grafikonu 2.

Tijekom provedenih prebrojavanja izračunata brojnost divlje svinje (svedena na cijelu površinu, gdje je istraživanje/ snimanje provedeno) na promatranoj površini kretala se u rasponu od 0 - 70 jedinki uz ar. sredinu od 24 grla. Relativna brojnost iznosila je $0,61+$ /- 0,53 grla po hektaru.

\section{RASPRAVA DISSCUSION}

Prilikom planiranja pokusa pokušalo se ustanoviti visinu leta bespilotne letjelice na kojoj bi se dobio dovoljno širok kut snimanja i prekrila dovoljno velika površina tj. zadovoljavajući intenzitet uzorka površine, a da pritom ne pada mogućnost detekcije snimanih životinja. Ustanovljeno je da je optimalna visina leta $100 \mathrm{~m}$. Na toj visini rezolucija kamere osigurava sigurnu detekciju divljači, a kut snimanja kamere osigurava pregled na prilično velikoj površini. Smanjivanjem visine, značajno se smanjuje površina koja se snima na račun bolje prostorne rezolucije, dok se podizanjem letjelice na visine sa svrhom obuhvaćanja veće površine, smanjuje vjerojatnost detekcije prebrojavane divljači, a time i povećava pogreška prebrojavanja. Praksa je pokazala da snimanje i video materijal olakšava prebrojavanje, budući da se jedinke kreću, pa ih je lakše uočiti. U praksi se također pokazalo da snimanja termalnom kamerom nisu moguća kod temperature zraka iznad $10^{\circ} \mathrm{C}$, budući da zbog zagrijavanja okoline (drveće, izbojci, teren) dolazi do smanjivanja kontrasta i otežane detekcije snimane divljači.

Testiranje obje metode pokazalo je relativnu konzistentnost brojnosti divlje svinje po jedinici površine za prvu metodu apsolutnog brojanja na površini $(1,26+/-0,18$ grla/ha). Kod metode brojanja divljači na transektima podaci su u puno širem rasponu ( 0 - 70 grla za istraživanu površinu od 39,5ha), što je na neki način i očekivano, budući se radi o uzorku intenziteta $10 \%$. Korištenjem te metode utvrđena brojnost po hektaru iznosila je nešto manje od $0,61 \mathrm{grla} / \mathrm{ha}$, ali i vrlo visok sd $=+/-0,53$ grla/ha. Iz ovoga se može zaključiti da je pouzdanije prebrojavanje prvom metodom, ukoliko se radi o manjim površinama. Međutim, ako se prebrojavanjem želi obuhvatiti neka veća površina, onda nije moguće primijeniti prvu metodu, već treba primjenjivati metodu transekta, koja generira i nešto veću pogrešku. Kako bi se pogreška takvog prebrojavanja smanjila, potrebno je povećati intenzitet ili pak povećati broj ponovnih prebrojavanja na transektima.

Još su 2014 god. Paneque-Gálvez i sur. ustanovili brojne prednosti snimanja šumskih ekosustava iz zraka bespilotnim letjelicama poput visoke prostorne rezolucije, potencijala za veliku vremensku rezoluciju, mogućnosti rada za oblačnog vremena, potencijala za $3 \mathrm{D}$ prikaz, relativno niske cijene, pristup nedostupnim područjima istovremeno ističući i neke nedostatke poput male nosivosti, niske spektralne rezolucije, osjetljivosti na atmosferske uvjete, kratkoće trajanja leta, mogućnosti sudara itd. Zasigurno je, da lake bespilotne letjelice imaju svoju budućnost i mogu uvelike pomoći u šumarstvu, zaštiti prirode, praćenju klimatskih primjena (Paneque-Gálvez i sur., 2014) i praćenju divljih životinja (Groom i sur., 2013; Myslenkov i Miquelle 2015). Perspektiva, izazovi i mogućnosti koje pružaju lake bespilotne letjelice opremljene različitim sofisticiranim ure- 
đajima i pratećim softverima programima osiguravaju nove aspekte istraživanja, zaštite i monitoringa šumskih i ostalih ekosustava. Neke postojeće tehnologije, koje svakim danom ulaze u primjenu kroz daljinska istraživanja putem bespilotnih letjelica, zamjenjuju i smanjuju potreban broj ljudi, smanjuju troškove, povećavaju preciznost i omogućuju do sada često nedostupan pristup,koji će se u budućnosti razvijati sve više. Tehničke karakteristike termalne kamere koja je korištena u ovom istraživanju, kao i kapacitet baterije bespilotne letjelice kao ograničavajući faktor primjene, u budućnosti će razvojem tehnologije biti usavršavani, a samim time doći će do razvoja novih metoda i promjene gledišta korištenja opisane tehnologije. Smanjivanje potrebnog broja ljudi i korištenjem metodologije, između ostalog i ovdje opisane metode, koja generira pogrešku sistematskog karaktera, dovesti će u budućnosti do stabilnijih i točnijih procjena svih trendova populacija divljači kojima se gospodari ili upravlja.

\section{LITERATURA}

\section{REFERENCES}

- Anonimus, 2015a: Pravilniku o sustavima bespilotnih zrakoplova. Narodne novine br. 49/15

- Anonimus, 2016b: Uredba o snimanju iz zraka. Narodne novine br. $70 / 16$

- Dowd, A., 2014: "Drone wars: risks and warnings". Retrieved 4

- Caniglia, R., 2008: Non-onvasive genetics and wolf Canis lupus population size estimation in the Northern Italian Apennines. Doctoral Thesis, Alma Mater Studiorum - Università di Bologna - Istituto Nazionale per la Fauna Selvatica, 84.

- Chabot, D., Bird, D. M., 2015: Wildlife research and management methods in the 21st century: Where do unmanned aircraft fit in?. J. Unmanned Veh. Syst. 3: 137-155. dx.doi.org/10.1139/ juvs-2015-0021.

- Gašparović, M., Seletković, A., Berta, A., Balenović, I. (2017): The Evaluation of Photogrammetry-Based DSM from Low-Cost UAV by LiDAR-Based DSM. SEFOR, 8 (2), s.117 - 125

- Google Earth, http://earth.google.com
- Groom, G., Stjernholm, M., Nielson, R.D., Fleetwood, A., Petersen, I.K. (2013): Remote sensing image data and automated analysis to describe marine bird distributions and abundances. Ecological Informatics, Volume 14, March 2013, Pages 2-8

- Jacobson, H. A.,J. C. Kroll, R. W. Browning, B. H. Koerth, M. H. Conway, 1997: Infrared-triggered cameras for censusing white-tailed deer. Wildlife Soc B, 25:547-556.

- Karanth, K.U.,J.D,. Nichols, N.S., Kumar, J.E. Hines, 2006: Assessing tiger population dynamics using photographic capturerecapture sampling. Ecology, 87(11): 2925-2937Massei, G., Genov, P. V., 2004: The enviromental impact of wild boar. Galemys16(nºspecial): 135-145.

- Miller, C.R., P. Joyce, L.P. Waits, 2005: A new method for estimating the size of small populationsfrom genetic mark-recapture data. Mol Ecol, 14: 1991-2005.

- Miller, J., Minear, P., Niessner, A., 2005: Intelligent Unmanned Air Vehicle Flight Systems. The Pennsylvania State University, U.S.A.

- Myslenkov, A. I., Miquelle, D. G., 2015: Comparison of Methods for Counting Hoofed Animal Density in Sikhote-Alin. Achievements in the Life Sciences 9: 1-8.

- Paneque-Gálvez, J.,. McCall, M. K,. Napoletano, B. M., Wich, S. A., Koh, L. P., 2014:Small Drones for Community-Based Forest Monitoring: An Assessment of Their Feasibility and Potential in Tropical Areas. Forests, 5: 1481-1507.

- Plhal R., J. Kamler, M. Homolka, Z. Adamec, 2011: An assessment of the applicability of photo trapping to estimate wild boar population density in a forest environment. Folia Zool, 60: 237 246.

- Seward, N. W., VerCauteren, K. C., Witmer, Gary, W., Engeman, R. M., 2004: Feral Swine Impacts on Agriculture and the Environment. Sheep \& Goat Research Journal, 12.

- Sutherland, W. J., 2006: Ecological Census Techniques: a handbook, Second edition. Cambridge University Press, The Edinburgh Building, , 432 pp, Cambridge.

- Tomljanović, K (2016): Lovnogospodarska osnova za državno otvoreno lovište III/39 “OPEKE II” za razdoblje 01.04.2016. 31.03. 2026.

- Tomljanović, K., Grubešić, M., Krapinec, K. 2010: Testiranje primjenjivosti digitalnih senzornih kamera za praćenje divljači i ostalih životinjskih vrsta. Šumarski list, 134(5-6), 287-292.

\section{SUMARY}

Different techniques and technologies are being used in wild animal research. Goals of such research and monitoring are various, most common are numbers per area and size of population for a researched species (Myslenkov i Miquelle, 2015). Development of new techniques and technologies that are used everyday in practial wild animal monitoring has made many tasks much easier and more precise, usage of technology often decreases the number of people needed to be involved in research and has made some until now unfeasable methods a reality. In conducted research we wanted to explore to what amount is it possible to apply a drone system equiped with thermal camera in assessing some population parameters for big game. Research was conducted in lowland teritorry of continental part of Republic of Croatia within hunting ground Opeka II. Wild boar has been chosen for the research as the most common species of big game in Republic of Croatia. Within two localities (I age grade of Oak forest) testing of two counting methods was conducted. First method was to try and count all 
neck within researched department. Given results show relatively high numbers of wild boar in average of 1,26 with sd=+/- 0,18 necks/ha within researched plane. Second utilized method was to count wild boar on in advance determined strips, whose share in total observed surface amounts to $10 \%$. In this method infomation are of bigger variability and somewhat smaller number off wild boar within observed plane has been determined in amount of 0,61 neck/ha with very high $s d=+/-0,53$. Researched confirmed the posibility of applying drone systems with thermal cameras. From two applied methods, first (absolute counting of all animals) is more suitable for smaller surfaces, while the method of appropriate strips is more suitable for larger surfaces with conscious risk of generating greater counting error.

KEY WORDS: lightweight unmanned aerial vehicles, drone, hunting management, remote sensing, wild boar (Sus scrofa), big game counting 